\title{
Melanin-concentrating hormone induces insulin resistance through a mechanism independent of body weight gain
}

\author{
Márcio Pereira-da-Silva, Cláudio T De Souza, \\ Alessandra L Gasparetti, Mário J A Saad and Lício A Velloso \\ Department of Internal Medicine, State University of Campinas, Brazil \\ (Requests for offprints should be addressed to L A Velloso, Departamento de Clínica Médica, FCM-UNICAMP, 13083-970 Campinas SP, Brazil; \\ Email: lavelloso@fcm.unicamp.br)
}

\begin{abstract}
Transgenic hyperexpression of melanin-concentrating hormone $(\mathrm{MCH})$ produces a phenotype of obesity and glucose intolerance. However, it is not known whether under this specific condition, glucose intolerance develops as a direct consequence of hyperexpressed $\mathrm{MCH}$ or is secondary to increased adiposity. Here, rats were treated i.c.v. with $\mathrm{MCH}$ or with an antisense oligonucleotide to $\mathrm{MCH}$ (MCH-ASO). $\mathrm{MCH}$ promoted an increase in blood glucose and a decrease in blood insulin levels during a glucose tolerance test. $\mathrm{MCH}$ also caused a decrease in the constant of glucose disappearance during an insulin tolerance test. All these effects of $\mathrm{MCH}$ were independent of body weight variation and were accompanied by
\end{abstract}

reduced insulin receptor substrate (IRS)-1 engagement of phosphatidylinositol-3 kinase (PI3-kinase) in white and brown adipose tissues, skeletal muscle and liver and by reduced Akt activation in skeletal muscle. $\mathrm{MCH}$ also led to a significant reduction in ERK activation in white adipose tissue. Finally, inhibition of hypothalamic $\mathrm{MCH}$ expression promoted a significant increase in ERK activation in brown adipose tissue. We conclude that hypothalamic $\mathrm{MCH}$ controls glucose homeostasis through mechanisms that are, at least in part, independent of adiposity.

Journal of Endocrinology (2005) 186, 193-201

\section{Introduction}

The hypothalamic neurotransmitter melanin-concentrating hormone $(\mathrm{MCH})$ is expressed predominantly in neurons of the lateral hypothalamus and participates in the control of energy expenditure and food intake ( $\mathrm{Qu}$ et al. 1996, Shimada et al. 1998). Transgenic, tissue-specific hyperexpression of this peptide leads to increased feeding accompanied by significantly higher body-weight and adiposity (Ludwig et al. 2001). Intracerebroventricular (i.c.v.) treatment with $\mathrm{MCH}$ also promotes body weight gain and increased food intake (Della-Zuana et al. 2002, Ito et al. 2003). Conversely, knockout of the $\mathrm{MCH}$ gene produces a lean phenotype, which is accompanied by reduced feeding and, most importantly, by increased resting energy expenditure (Shimada et al. 1998).

Although most studies have emphasized the role for $\mathrm{MCH}$ in feeding and energy homeostasis, transgenic mice hyperexpressing $\mathrm{MCH}$ in the hypothalamus also display an interesting phenotype of insulin resistance (Ludwig et al. 2001). According to this study, these transgenic mice present a significantly higher blood glucose level during an intraperitoneal glucose tolerance test (ipGTT), which is accompanied by a markedly increased fed blood insulin level and by severe insulin resistance, as measured by the insulin tolerance test (ITT). Although the authors state that, in this particular situation, insulin resistance develops secondarily to body weight gain, they do not discard the possibility of a direct effect of $\mathrm{MCH}$ in regulating peripheral insulin action and insulin production.

Considering the important epidemiological association between obesity and diabetes mellitus (Kopelman 2000, Flier 2004), the characterization of mechanisms that simultaneously participate in the control of body weight and insulin action may reveal novel candidates for combined therapeutic approaches for both diseases. Therefore, the objective of the present study was to evaluate the effect of short-term i.c.v. treatment with exogenous $\mathrm{MCH}$ upon whole-body glucose homeostasis, and upon insulin signal transduction in liver, skeletal muscle, and white and brown adipose tissues of non-genetically manipulated, non-diabetes prone Wistar rats.

\section{Materials and Methods}

Chemicals, antibodies and oligonucleotides

Reagents for SDS/PAGE and immunoblotting were obtained from Bio-Rad (Richmond, CA, USA). 
Hepes, PMSF, aprotinin, dithiothreitol (DTT), Triton X-100, Tween 20, glycerol, BSA (fraction V) and rat $\mathrm{MCH}$ (M-4542), were from Sigma Chemical Co. (St Louis, MO, USA). Protein A-Sepharose $6 \mathrm{MB}$ was from Pharmacia (Uppsala, Sweden), ${ }^{125}$ I-Protein A and nitrocellulose membranes were from Amersham Corp. (Aylesbury, Bucks, UK). Phosphorthioate-modified oligonucleotides for $\mathrm{MCH}$ (sense, $5^{\prime}$-CCC TCA GTC TGG CTG-3' and anti-sense, 5'-ACA GCC AGA CTG AGG$3^{\prime}$ ) were obtained from Life Technologies (GIBCO BRL, Gaithersburg, MD, USA). Sodium amobarbital and insulin were from Eli Lilly (Indianapolis, IN, USA). Polyclonal anti-phosphotyrosine antibodies were raised in rabbits and affinity-purified on phosphotyramine columns (Pang et al. 1985). Anti-insulin receptor (IR), anti-insulin receptor substrate (IRS)-1, anti-IRS-2, anti-ERK, anti-pERK (apERK/Tyr 204, detecting pERK42 and pERK44), anti-Akt1, and anti-phospho $\left[\mathrm{Ser}^{473}\right]$ Akt1 were from Santa Cruz Biotechnology (Santa Cruz, CA, USA). Rabbit antip85/phosphatidylinositol-3 kinase (PI3-kinase) antiserum was from UBI (Lake Placid, NY, USA). Insulin (Scott et al. 1981), corticosterone (Amersham Corp., Biotrak, Aylesbury, Bucks, UK) and MCH (Phoenix Pharmaceutical Inc., Belmont, CA, USA) were determined by RIA. Glucose was determined by the glucose oxidase method (Trinder 1969).

\section{Intracerebroventricular (i.c.v.) cannulation and i.c.v. injection}

Chronic unilateral 26-gauge stainless steel indwelling guide cannulas were stereotaxically and aseptically placed into the lateral ventricle $(0.2 \mathrm{~mm}$ posterior, $1.5 \mathrm{~mm}$ lateral and $4.2 \mathrm{~mm}$ ventral to bregma) of adult male Wistar rats under sodium amobarbital (15 mg/ $\mathrm{kg}$ body weight) anesthesia, as previously described (Della-Zuana et al. 2002). After a one-week recovery period, all rats were kept in individual cages and i.c.v.-treated with vehicle (TE buffer, $10 \mathrm{mM}$ Tris-HCl, $1.0 \mathrm{mM}$ EDTA), exogenous $\mathrm{MCH}, \mathrm{MCH}$ sense, or $\mathrm{MCH}$ antisense $(\mathrm{MCH}-$ ASO) phosphorthioate-modified oligonucleotides. $\mathrm{MCH}$ $(2.0 \mu \mathrm{g}), \mathrm{MCH}$ sense $(4.0$ nmoles $)$ and $\mathrm{MCH}-\mathrm{ASO}$ $(4.0$ nmoles $)$ were diluted in TE buffer and injected once a day at $1000 \mathrm{~h}$ for four days, with a total volume of $2 \cdot 0 \mu \mathrm{l}$ per dose. Rats were randomly assigned to four different treatment conditions: TE treatment (control), $\mathrm{MCH}$ treatment $(\mathrm{MCH})$, antisense $\mathrm{MCH}$ oligonucleotide treatment (MCH-ASO), and $\mathrm{MCH}$ sense treatment. Since $\mathrm{MCH}$ sense treatment did not modulate hypothalamic $\mathrm{MCH}$ concentration, glucose and insulin blood levels and insulin signal transduction, we did not include these data in the results section. Data on the characterization in $\mathrm{MCH}$ sense and $\mathrm{MCH}-\mathrm{ASO}$ have been published previously (Pereira-da-Silva et al. 2003). MCH-ASO promoted a reduction in $\mathrm{MCH}$ tissue hypothalamic concentration from $0.42 \pm 0.07 \mathrm{pmol} / \mathrm{mg}$ (control) to $0.34 \pm 0.04 \mathrm{pmol} / \mathrm{mg}$ $(\mathrm{MCH}-\mathrm{ASO}) \quad(n=5, \quad P<0 \cdot 05)$. Food intake and body weight were determined daily at $1000 \mathrm{~h}$. The results of food intake are expressed as mean daily consumption (g) during the experimental period, and the results of body weight are expressed as the variation of body weight (g) from the first to the last experimental day.

\section{Glucose tolerance test (GTT)}

Intraperitoneal (ip) GTT was carried out at the end of the experimental period, on day 5, after an overnight fast. After collection of an unchallenged sample (time 0), a solution of $20 \%$ glucose $(2 \cdot 0 \mathrm{~g} / \mathrm{kg}$ body weight $)$ was administered into the peritoneal cavity. Blood samples were collected from the tail at $0,15,30,60$ and $120 \mathrm{~min}$ for determination of glucose and insulin concentrations.

\section{Insulin tolerance test (ITT)}

Intraperitoneal (ip) ITT was performed on experimental day five, after an overnight fast. Insulin $(6 \mu \mathrm{g})$ was injected intraperitoneally and blood samples were collected from the tail at $0,5,10,15,20,25$ and 30 min for serum glucose determination. The constant rate for glucose disappearance $\left(\mathrm{K}_{i t t}\right)$ was calculated using the formula $0 \cdot 693 / \mathrm{t}_{1 / 2}$. Glucose $t_{1 / 2}$ was calculated from the slope of the least-square analysis of plasma glucose concentrations during the linear decay phase (Bonora et al. 1987).

\section{Tissue extraction, immunoblotting and immunoprecipitation}

The abdominal cavity of anesthetized rats was opened and the rats received an infusion of insulin $\left(0 \cdot 2 \mathrm{ml}, 10^{-6} \mathrm{M}\right)$ or saline $(0.2 \mathrm{ml})$ through the vena cava. After different intervals ( 2 min for IR, IRS-1, IRS-2 and PI3-kinase and $5 \mathrm{~min}$ for Akt and ERK), fragments $(3.0 \times 3.0 \times 3.0 \mathrm{~mm})$ of brown adipose tissue (BAT), white adipose tissue (WAT) (epididymal fat), liver and skeletal muscle (gastrocnemius muscle) were excised and immediately homogenized in solubilization buffer at $4{ }^{\circ} \mathrm{C}(1 \%$ Triton $\mathrm{X}-100,100 \mathrm{mM}$ Tris- $\mathrm{HCl}$ (pH 7·4), $100 \mathrm{mM}$ sodium pyrophosphate, $100 \mathrm{mM}$ sodium fluoride, $10 \mathrm{mM}$ EDTA, $10 \mathrm{mM}$ sodium orthovanadate, $2 \cdot 0 \mathrm{mM}$ PMSF and $0 \cdot 1 \mathrm{mg}$ aprotinin $/ \mathrm{ml}$ ) with a Polytron PTA 20 S generator (model PT 10/35; Brinkmann Instruments, Westbury, NY, USA) operated at maximum speed for $30 \mathrm{~s}$. Insoluble material was removed by centrifugation for $20 \mathrm{~min}$ at $9000 \mathrm{~g}$ in a 70.Ti rotor (Beckman) at $4{ }^{\circ} \mathrm{C}$. The protein concentration of the supernatants was determined by the Bradford dye binding method. Aliquots of the resulting supernatants containing $5.0 \mathrm{mg}$ total protein were used for immunoprecipitation with antibodies against IR, IRS-1 and IRS-2 at $4{ }^{\circ} \mathrm{C}$ overnight, followed by SDS/PAGE, transfer to nitrocellulose membranes and blotting with antiphosphotyrosine, anti-IR, anti-IRS-1, anti-IRS-2 or anti-p85/ PI3-kinase. In direct immunoblot experiments, $0.2 \mathrm{mg}$ protein extracts obtained from each tissue were separated 
Table 1 Metabolic and hormonal characteristics of rats treated with $\mathrm{MCH}$ antisense oligonucleotide (ASO) and exogenous $\mathrm{MCH}$, compared with control. Results are means \pm S.E.M., $n=6$

\begin{tabular}{|c|c|c|c|}
\hline & Control & ASO & $\mathrm{MCH}$ \\
\hline Food ingestion $(\mathrm{g} / 24 \mathrm{~h})$ & $18 \cdot 3 \pm 1 \cdot 4$ & $17 \cdot 0 \pm 1 \cdot 1$ & $21 \cdot 2 \pm 2 \cdot 2$ \\
\hline Body weight variation ( $\mathrm{g} / 5$ days) & $+9 \cdot 3 \pm 1 \cdot 8$ & $-2 \cdot 2 \pm 0 \cdot 5^{*}$ & $+11 \cdot 3 \pm 1 \cdot 9$ \\
\hline Plasma insulin $(\mathrm{ng} / \mathrm{ml})$ & $1 \cdot 86 \pm 0 \cdot 43$ & $1 \cdot 63 \pm 0.38$ & $1 \cdot 28 \pm 0 \cdot 40$ \\
\hline Serum glucose $(\mathrm{mg} / \mathrm{dl})$ & $80 \cdot 8 \pm 2 \cdot 1$ & $83 \cdot 2 \pm 2 \cdot 9$ & $90 \cdot 7 \pm 2 \cdot 2^{*}$ \\
\hline Serum corticosterone $(\mathrm{ng} / \mathrm{ml})$ & $98 \cdot 5 \pm 8.9$ & $92 \cdot 4 \pm 7 \cdot 7$ & $111 \cdot 4 \pm 12 \cdot 3$ \\
\hline
\end{tabular}

${ }^{*} P<0 \cdot 05$ compared with control.

by SDS-PAGE, transferred to nitrocellulose membranes and blotted with anti-IR, -IRS-1, -IRS-2, -phospho-Akt or -phospho-ERK antibodies as described (Torsoni et al. 2003). To assure proper loading of proteins onto the gels, the nitrocellulose membranes used to evaluate phospho-Akt or phospho-ERK were always reprobed with antibodies against Akt and ERK respectively.

\section{Data presentation and statistical analysis}

All numerical results are expressed as the mean \pm S.E.M. of the indicated number of experiments. The results of blots are presented as direct comparisons of bands in autoradiographs and quantified by densitometry using the Scion Image software (ScionCorp, Frederick, MD, USA). Data were analyzed by the two-tailed unpaired Student's $t$-test or by repeat-measures analysis of variance (one-way or two-way ANOVA) followed by post hoc analysis of significance (Bonferroni test) when appropriate, comparing experimental and control groups. The level of significance was set at $P<0 \cdot 05$.

\section{Results}

\section{Metabolic characterization of experimental animals}

Treatment of rats with $\mathrm{MCH}$ or $\mathrm{MCH}-\mathrm{ASO}$ for four days did not modify mean daily food intake, basal plasma insulin levels and basal serum corticosterone levels (Table 1). Treatment with $\mathrm{MCH}$ promoted a significant increase in basal glucose levels, while treatment with $\mathrm{MCH}-\mathrm{ASO}$ led to a significant reduction in 5-day body mass variation (Table 1). Intracerebroventricular $\mathrm{MCH}$ led to no variation in body weight (Table 1). During a GTT, the blood levels of glucose were constantly higher in $\mathrm{MCH}$-treated rats (Fig. 1A), which resulted in a significantly higher area under the glucose curve (Fig. 1B). The levels of plasma insulin during the GTT were also affected by $\mathrm{MCH}$ treatment (Fig. 1C), which produced a significant reduction in the area under the insulin curve (Fig. 1D). Finally, during ITT, the constant of glucose decay was significantly impaired by the treatment with $\mathrm{MCH}$ (Fig. 1E). The inhibition of $\mathrm{MCH}$ expression with $\mathrm{MCH}-\mathrm{ASO}$ did not modify glucose and insulin levels during the GTT and did not interfere with glucose mobilization during the ITT (Fig. 1).

\section{Insulin signal transduction in peripheral tissues}

The treatments with $\mathrm{MCH}$ and $\mathrm{MCH}-\mathrm{ASO}$ did not affect the expression of IR, IRS-1 and IRS-2 in skeletal muscle, liver, WAT and BAT of rats (Fig. 2). Conversely, the treatment with $\mathrm{MCH}$ led to significant inhibition of insulin-induced association of IRS-1 with p85PI3-kinase in skeletal muscle (Fig. 3), in liver (Fig. 4), in WAT (Fig. 5) and in BAT (Fig. 6). This was followed by a significant inhibition of insulin-induced $\left[\mathrm{Ser}^{473}\right]$ phosphorylation of Akt in skeletal muscle (Fig. 3) and by a significant inhibition of insulin-induced $\left[\mathrm{Tyr}^{204}\right]$ phosphorylation of ERK in WAT (Fig. 5). Finally, the treatment of rats with $\mathrm{MCH}-\mathrm{ASO}$ promoted a significant increase in insulin-induced $\left[\mathrm{Tyr}^{204}\right.$ ] phosphorylation of ERK in BAT (Fig. 6).

\section{Discussion}

In recent years, important advances have been made in the characterization of the mechanisms that link obesity to type 2 diabetes. Leptin and insulin, by acting upon specific neurons of the arcuate nucleus, deliver anorexygenic and adipostatic signals to the hypothalamus. Central resistance to these hormones' actions is thought to play an important role in the pathogenesis of obesity by disrupting a complex network of neurotransmitters that coordinate the balance between food intake and energy expenditure (Schwartz et al. 2000, Flier 2004). MCH is one of such hypothalamic neurotransmitters that are modulated in response to leptin and insulin (Schwartz et al. 2000, Segal-Lieberman et al. 2003). The action of these hormones upon hypothalamic circuitries is initiated by the coordinated inhibition or stimulation of neuropeptide Y (NPY)/agouti-related peptide (AGRP)ergic and pro-opiomelanocortin (POMC)ergic $(\alpha-$ melanocyte-stimulating hormone $(\alpha-\mathrm{MSH})$ and cocaine 
A.

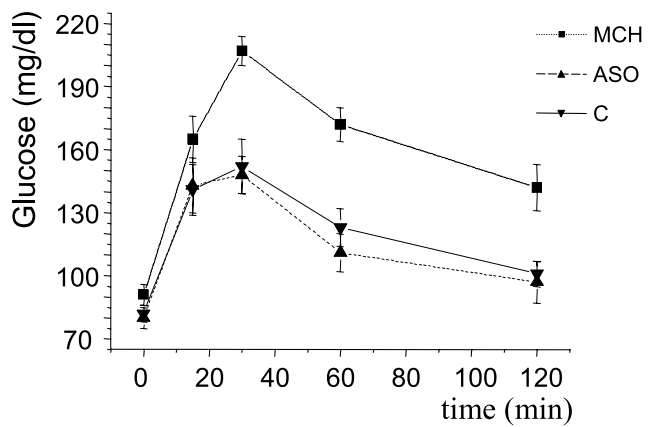

C.

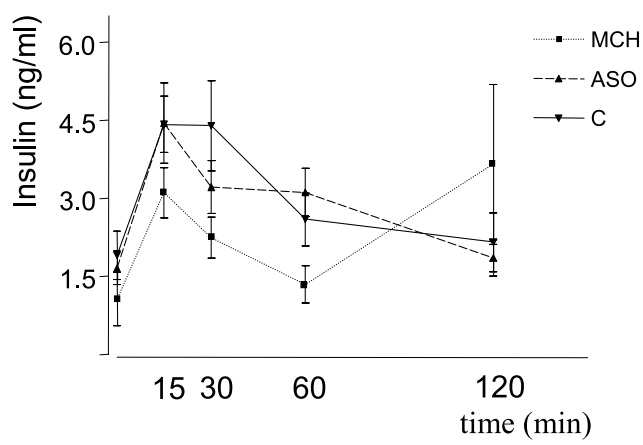

E.

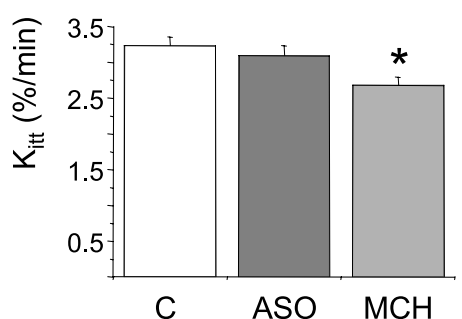

B.

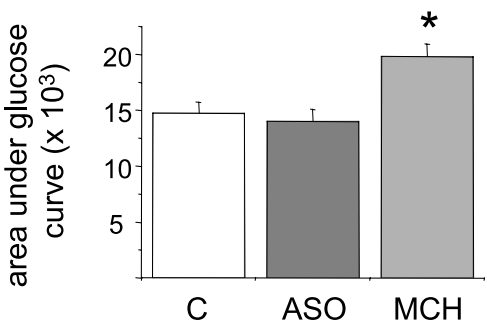

D.

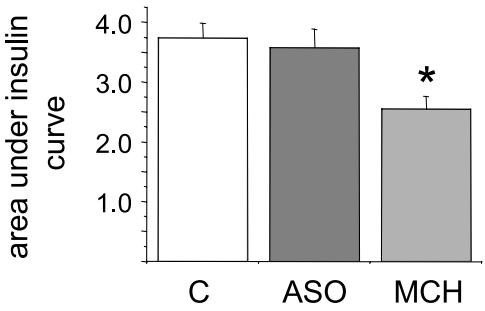

Figure 1 Serum glucose levels (A), and area under the glucose curve (B), and plasma insulin levels (C), and area under the insulin curve (D) during the ipGTT. (E) Constant of glucose decay $\left(\mathrm{K}_{i t t}\right)$ during the ipITT. Intracerebroventricular cannulated rats were treated with saline (C), $\mathrm{MCH}$ or MCH-ASO (ASO) according to protocols described under Materials and Methods. For all experiments $n=6$; ${ }^{*} P<0 \cdot 05$ compared with control (C).

and amphetamine-related transcript (CART) producing) neurons of the arcuate nucleus respectively. These first-order neurons are connected with downstream second-order neurons located at the periventricular and lateral hypothalamic nuclei. Reduction in NPY/AGRP and increase in $\alpha-\mathrm{MSH} / \mathrm{CART}$ at the nerve terminals promote increases of anorexigenic and pro-thermogenic neurotransmitters such as corticotropin-releasing hormone and thyrotropin-releasing hormone at the periventricular nucleus and reduction of orexigenic and energy sparing neurotransmitters such as orexin and $\mathrm{MCH}$ at the lateral hypothalamic nucleus (Segal-Lieberman et al. 2003, Flier 2004). Since transgenic mice hyperexpressing $\mathrm{MCH}$ are obese and insulin resistant, a role for $\mathrm{MCH}$ as a central controller of insulin secretion and/or action has been proposed (Ludwig et al. 2001).

In the present study, we demonstrate that short-term i.c.v. treatment of rats with $\mathrm{MCH}$ does not modify food intake and body weight but does modulate the blood levels of glucose and insulin, leading to glucose intolerance, reduced glucose-stimulated insulin secretion and insulin resistance. All these effects were accompanied by the 
A.

IB: IR

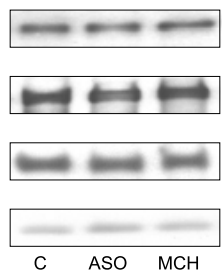

B.

IB: IRS-1

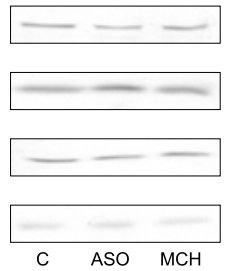

C.

IB: IRS-2

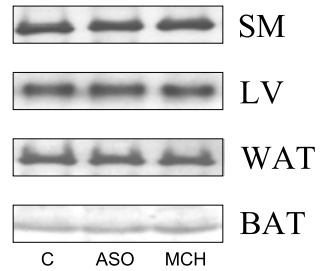

Figure 2 Immunoblot (IB) analysis of (A) IR, (B) IRS-1 and (C) IRS-2 expression in skeletal muscle (SM), liver (LV), white adipose tissue (WAT) and brown adipose tissue (BAT) of i.c.v. cannulated rats treated with saline (C), MCH-ASO (ASO) or $\mathrm{MCH}$ according to protocols described under Materials and Methods. In all experiments, $n=5$.

modulation of insulin-induced association of IRS-1 with PI3-kinase in skeletal muscle, liver, and white and brown adipose tissues and, especially, by reduced insulin-induced molecular activation of Akt in skeletal muscle. In insulinsensitive tissues such as skeletal muscle and adipose tissue, Akt connects insulin signal transduction through the

IRSs/PI3-kinase pathway for the control of GLUT-4 translocation from intracellular pools to the cell membrane (Saltiel \& Kahn 2001). Therefore, Akt plays a pivotal role in the linkage between the insulin signal and the control of glucose uptake (Saltiel \& Kahn 2001). Skeletal muscle is responsible for most of the glucose clearance controlled by insulin (Shulman 2000). Thus, we believe that the inhibitory effect of short-term i.c.v. $\mathrm{MCH}$ treatment upon insulin action is mostly dependent on molecular resistance to insulin action through Akt in skeletal muscle. Despite the finding that i.c.v. $\mathrm{MCH}$ promoted an apparent impairment of the insulin-induced association of IRS-1 with PI3-kinase in the other tissues tested, this was not translated into the regulation of a more distal event such as the activation of Akt. The reason for these divergent outcomes in different tissues is unknown; however, in a number of animal models of insulin resistance tissuespecific modulation of insulin action has been reported. In a recent study, Rojas et al. (2003) have shown that in two different models of insulin resistance, epinephrine- and dexamethasone-treated rats, the expression and functional activation of elements of the insulin signaling pathway occur divergently when comparing liver and skeletal

B.

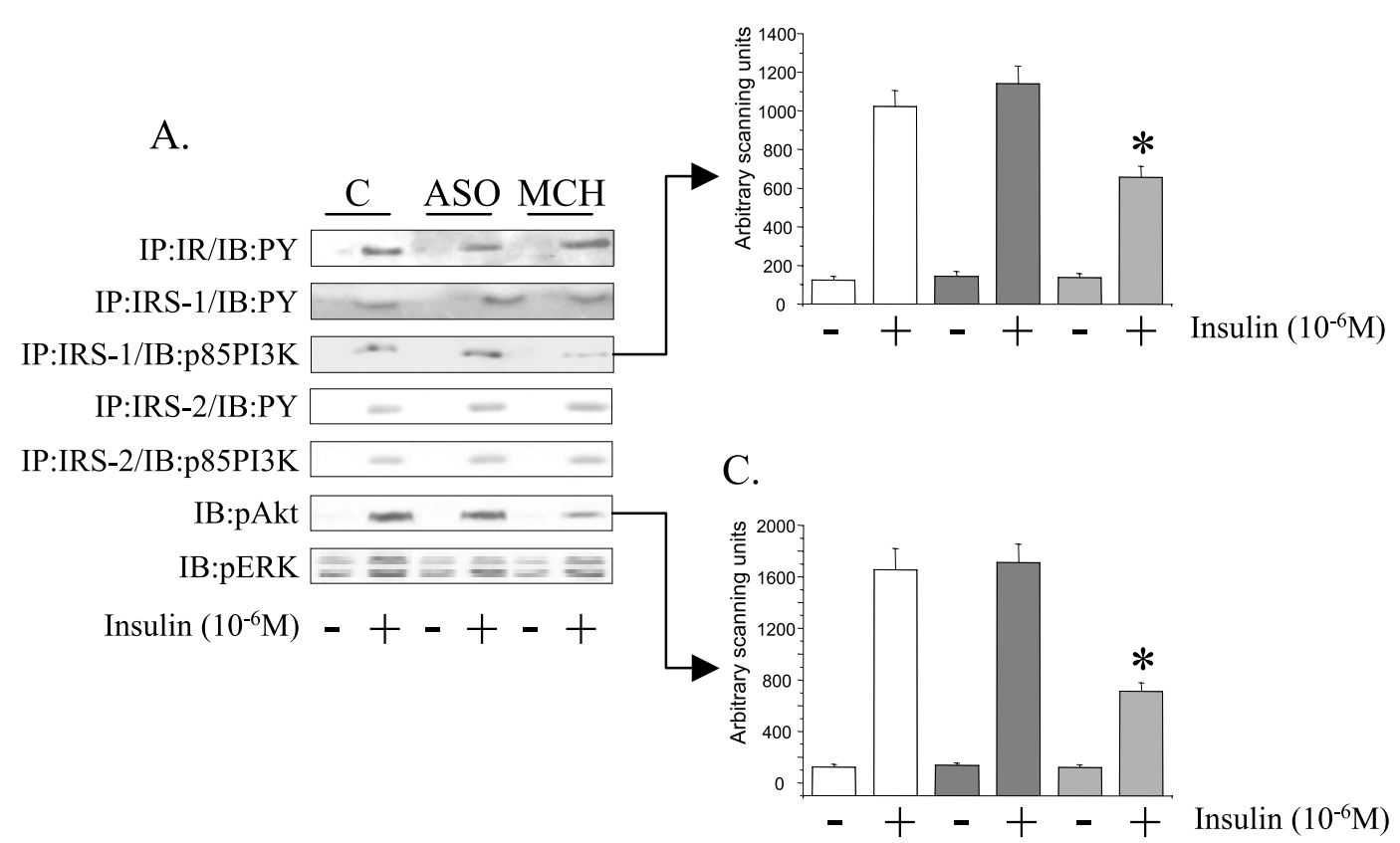

Figure 3 Evaluation of insulin signal transduction in skeletal muscle of rats treated i.c.v. with saline (C), $\mathrm{MCH}-\mathrm{ASO}$ (ASO) or $\mathrm{MCH}$ according to protocols described under Materials and Methods. Samples of skeletal muscle protein extracts obtained from rats acutely treated iv with saline $(-)$ or insulin $(+)$ were directly separated by SDS-PAGE or employed in immunoprecipitation (IP) assays with anti-IR, -IRS-1 and -IRS-2 antibodies rendering immunoprecipitates that were thereafter separated by SDS-PAGE. After electrophoresis the proteins were transferred to nitrocellulose membranes and blotted (IB) with anti-phosphotyrosine (PY), -p85PI3-kinase (p85PI3K), $-p\left[\mathrm{Ser}^{473}\right] \mathrm{Akt}(\mathrm{pAkt})$ or $-\mathrm{p}\left[\mathrm{Tyr}^{204}\right]$ ERK (pERK) antibodies. Only proteins that suffered significant modulation by any of the treatment protocols have their data graphically represented (in B and C). Open bars, control; darker shaded bars, $\mathrm{MCH}$-ASO; lighter shaded bars, $\mathrm{MCH}$. For all experiments, $n=5 ;{ }^{*}<<0.05$ compared with control (C). 
A.

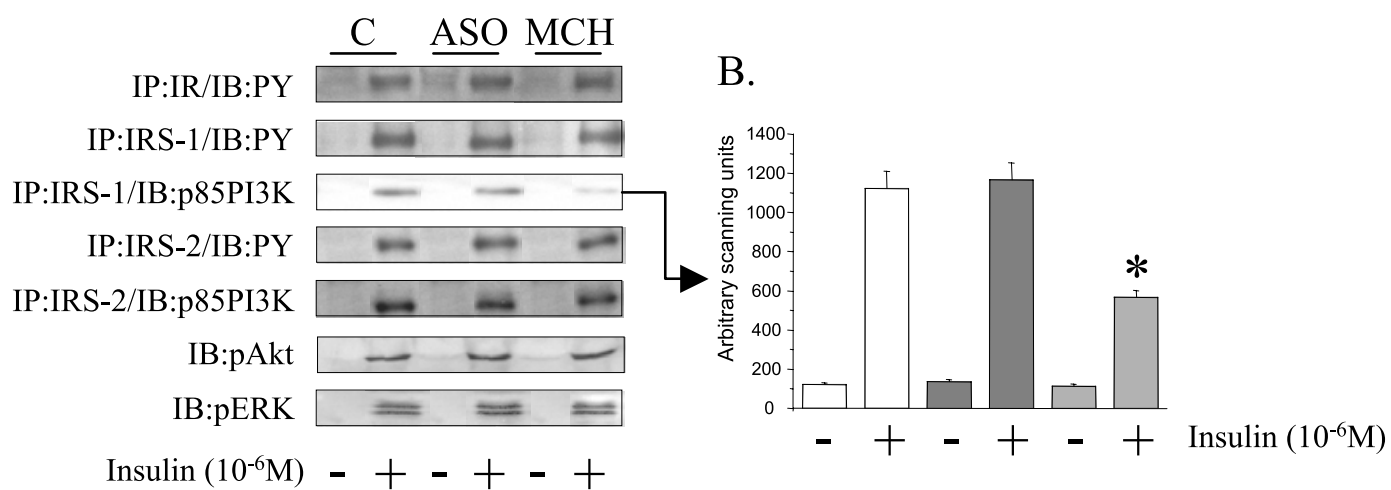

Figure 4 Evaluation of insulin signal transduction in liver of rats treated i.c.v. with saline (C), MCH-ASO (ASO) or $\mathrm{MCH}$ according to protocols described under Materials and Methods. Samples of liver protein extracts obtained from rats acutely treated iv with saline $(-)$ or insulin $(+)$ were directly separated by SDS-PAGE or employed in immunoprecipitation (IP) assays with anti-IR, -IRS-1 and -IRS-2 antibodies rendering immunoprecipitates that were thereafter separated by SDS-PAGE. After electrophoresis the proteins were transferred to nitrocellulose membranes and blotted (IB) with anti-phosphotyrosine (PY), -p85PI3-kinase (p85PI3K), -p[Ser $\left.{ }^{473}\right]$ Akt (pAkt) or -p[Tyr $\left.{ }^{204}\right]$ ERK $(\mathrm{pERK})$ antibodies. Only proteins that underwent significant modulation by any of the treatment protocols have their data graphically represented (in B). Open bars, control; darker shaded bars, $\mathrm{MCH}-\mathrm{ASO}$; lighter shaded bars, $\mathrm{MCH}$. For all experiments, $n=5 ;{ }^{*} P<0 \cdot 05$ compared with control (C).

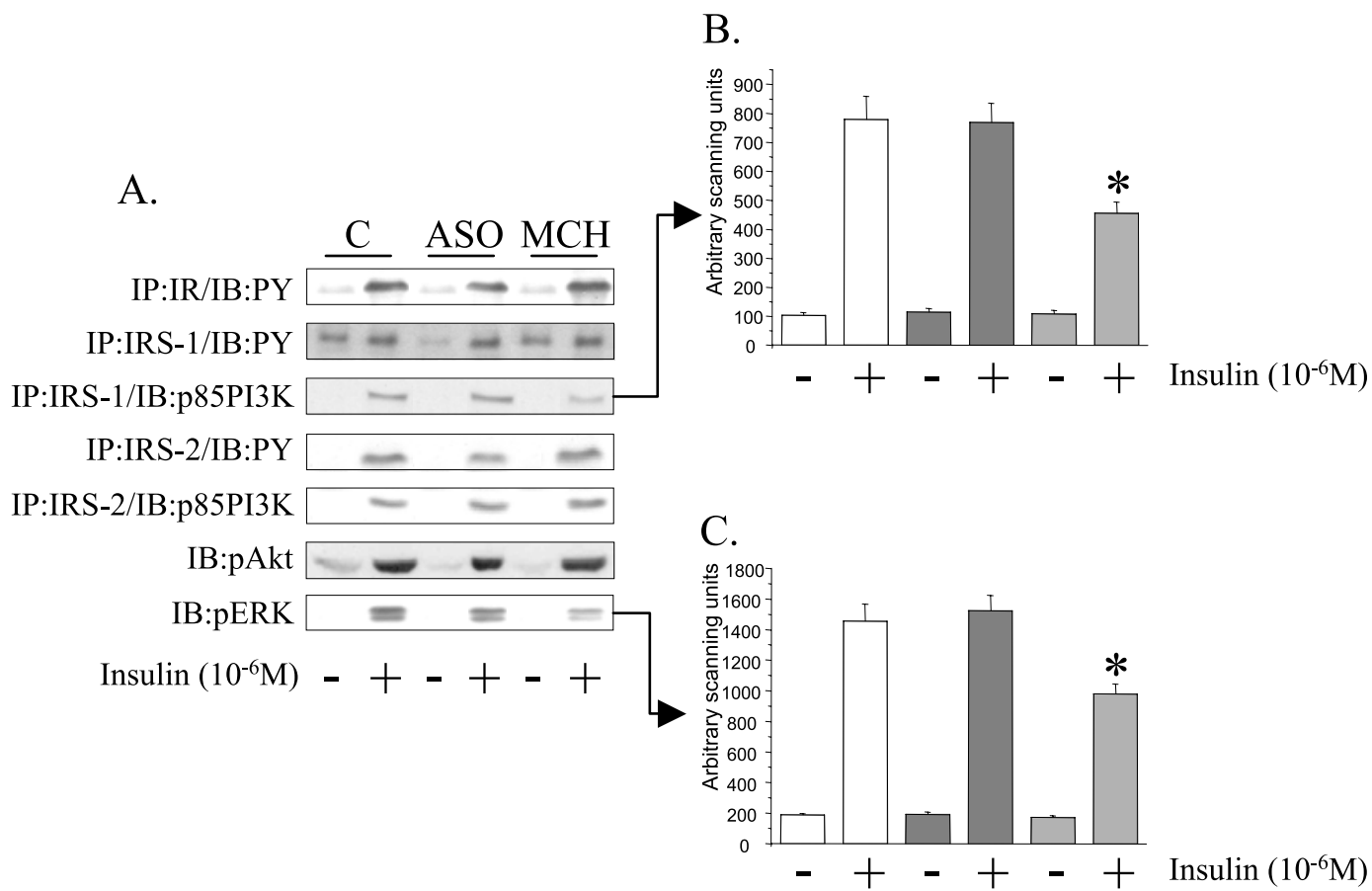

Figure 5 Evaluation of insulin signal transduction in white adipose tissue of rats treated i.c.v. with saline (C), $\mathrm{MCH}$-ASO (ASO) or $\mathrm{MCH}$ according to protocols described under Materials and Methods. Samples of white adipose tissue protein extracts obtained from rats acutely treated iv with saline $(-)$ or insulin $(+)$ were directly separated by SDS-PAGE or employed in immunoprecipitation (IP) assays with anti-IR, -IRS-1 and -IRS-2 antibodies rendering immunoprecipitates that were thereafter separated by SDS-PAGE. After electrophoresis, the proteins were transferred to nitrocellulose membranes and blotted (IB) with anti-phosphotyrosine (PY), -p85PI3-kinase (p85PI3K), $-\mathrm{p}\left[\mathrm{Ser}^{473}\right] \mathrm{Akt}(\mathrm{pAkt})$ or $-\mathrm{p}\left[\mathrm{Tyr}^{204}\right] \mathrm{ERK}(\mathrm{pERK})$ antibodies. Only proteins that underwent significant modulation by any of the treatment protocols have their data graphically represented (in B and C). Open bars, control; darker shaded bars, $\mathrm{MCH}$-ASO; lighter shaded bars, $\mathrm{MCH}$. For all experiments, $n=5$; ${ }^{*} P<0.05$ compared with control (C). 
B.

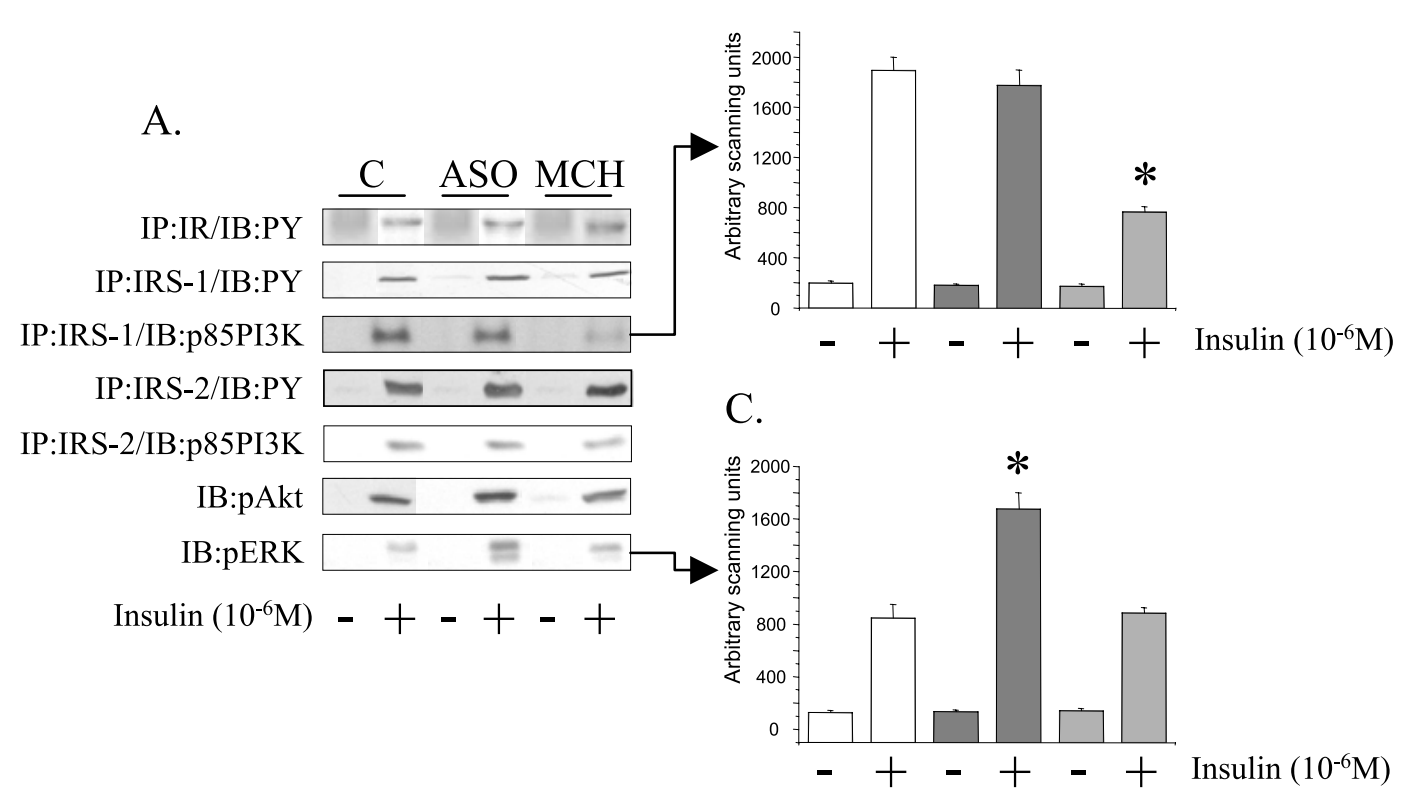

Figure 6 Evaluation of insulin signal transduction in brown adipose tissue of rats treated i.c.v. with saline (C), $\mathrm{MCH}-\mathrm{ASO}$ (ASO) or $\mathrm{MCH}$ according to protocols described under Materials and Methods. Samples of brown adipose tissue protein extracts obtained from rats acutely treated iv with saline $(-)$ or insulin $(+)$ were directly separated by SDS-PAGE or employed in immunoprecipitation (IP) assays with anti-IR, -IRS-1 and -IRS-2 antibodies rendering immunoprecipitates that were thereafter separated by SDS-PAGE. After electrophoresis, the proteins were transferred to nitrocellulose membranes and blotted (IB) with anti-phosphotyrosine (PY), -p85PI3-kinase (p85PI3K), $-\mathrm{p}\left[\mathrm{Ser}^{473}\right]$ Akt (pAkt) or - $\left[\mathrm{Tyr}^{204}\right]$ ERK (pERK) antibodies. Only proteins that underwent significant modulation by any of the treatment protocols have their data graphically represented (in B and C). Open bars, control; darker shaded bars, $\mathrm{MCH}$-ASO; lighter shaded bars, $\mathrm{MCH}$. For all experiments, $n=5 ;{ }^{*} P<0 \cdot 05$ compared with control $(\mathrm{C})$.

muscle. In another study, Gasparetti et al. (2003) have shown that the exposure of rats to a cold environment modulates insulin action and this is associated with a tissue-specific modulation of insulin signal transduction. In a very elegant study, Crozier et al. (2003) provided evidence for a tissue-specific regulation of protein synthesis induced by insulin. Finally, in one of the first studies of insulin signal transduction in animal models of insulin resistance, Saad et al. (1992) reported a similar tissue specificity concerning the activation of elements of the insulin signaling cascade.

In addition to looking at the activation of the metaboliccontrolling PI3-kinase/Akt pathway, we also evaluated the consequences of $\mathrm{MCH}$ and $\mathrm{MCH}-\mathrm{ASO}$ i.c.v. treatment upon the growth- and mitogenic-controlling ERK pathway; we found that the inhibition of hypothalamic $\mathrm{MCH}$ expression by $\mathrm{MCH}-\mathrm{ASO}$ promoted a significant increase in insulin-induced ERK activation in BAT, while i.c.v. $\mathrm{MCH}$ promoted a reduction in insulin-induced activation of ERK in WAT. MCH is known to act as an energy-sparing neurotransmitter (Pereira-da-Silva et al. 2003, Segal-Lieberman et al. 2003) and in a recent study we have shown that inhibition of $\mathrm{MCH}$ expression leads to the increase of uncoupling protein-1 (UCP-1) expres- sion in BAT which is known to increase energy expenditure rates (Pereira-da-Silva et al. 2003). Considering that adrenergic stimulation of UCP-1 expression in BAT depends on ERK activation (Valladares et al. 2000), we suggest that the short-term treatment of rats with $\mathrm{MCH}-$ ASO promotes increased sympathetic signaling to BAT, which engages ERK. Conversely, the ability of $\mathrm{MCH}$ to reduce insulin-induced activation of ERK in WAT may be a distal consequence of impaired insulin action in this tissue. In fact, in another experimental model known to maintain increased $\mathrm{MCH}$ expression in the hypothalalmus, i.e. cold-exposure, impairment of the insulin signal transduction through ERK is also observed (Gasparetti et al. 2003).

Finally, in addition to its effects upon insulin signal transduction, short-term i.c.v. MCH treatment promoted an interesting inhibition of glucose-stimulated insulin secretion. A detailed look at the glucose-induced insulin curve suggests that $\mathrm{MCH}$ promotes a blunting of the first phase, which is followed by a late increase in insulin secretion. Interestingly, the loss of first phase insulin secretion is a hallmark of insulin-resistance and type 2 diabetes (Steppel \& Horton 2004). Although we have not evaluated the mechanism involved in this phenomenon 
we believe it was mediated by neural inputs. In two recent studies we observed that during cold-exposure there is an increased expression of $\mathrm{MCH}$ in the hypothalamus of rats (Pereira-da-Silva et al. 2003). This is accompanied by a reduction in glucose-stimulated insulin secretion which is mediated by sympathetic but not by parasympathetic inputs (De Souza et al. 2003).

The present study does not discriminate as to whether the effects of short-term $\mathrm{MCH}$ treatment are due to regulation of neural connections from the hypothalamus to the peripheral organs or due to indirect mechanisms such as the control of peripheral hormonal levels. The fact that the treatment protocol was not acute would favor the possibility of an indirect effect. However, since the blood levels of corticosterone were not affected by the treatment and insulin levels were reduced, we believe that the case for the participation of neural mechanisms is strengthened. Moreover, since the period of treatment was very short, and no significant modulation of body weight was detected in $\mathrm{MCH}$-treated rats, we can state that the effects of hypothalamic $\mathrm{MCH}$ upon insulin physiological activity and molecular signaling are independent of body mass gain. The present study provides important information to support a role for neural mechanisms in the induction of insulin resistance and development of diabetes. Moreover, $\mathrm{MCH}$ is ratified as a potential target for therapeutic actions in obesity and diabetes.

\section{Acknowledgements}

The present studies were funded by grants from Fundação de Amparo à Pesquisa do Estado de São Paulo (FAPESP) and by Conselho Nacional de Desenvolvimento Científico e Tecnológico (CNPq). We are indebted to Dr Nicola Conran for English grammar editing. The authors declare that there is no conflict of interest that would prejudice the impartiality of this scientific work.

\section{References}

Bonora E, Manicardi V, Zavaroni I, Coscelli C \& Butturini U 1987 Relationships between insulin secretion, insulin metabolism and insulin resistance in mild glucose intolerance. Diabetes and Metabolism 13 116-121.

Crozier SJ, Anthony JC, Schworer CM, Reiter AK, Anthony TG, Kimball SR \& Jefferson L S 2003 Tissue-specific regulation of protein synthesis by insulin and free fatty acids. American Journal of Physiology - Endocrinology and Metabolism 285 E754-E762.

De Souza CT, Gasparetti AL, Pereira-da-Silva M, Araujo EP, Carvalheira JB, Saad MJ, Boschero AC, Carneiro EM \& Velloso LA 2003 Peroxisome proliferator-activated receptor gamma coactivator-1-dependent uncoupling protein-2 expression in pancreatic islets of rats: a novel pathway for neural control of insulin secretion. Diabetologia 46 1522-1531.

Della-Zuana O, Presse F, Ortola C, Duhault J, Nahon JL \& Levens N 2002 Acute and chronic administration of melanin-concentrating hormone enhances food intake and body weight in Wistar and Sprague-Dawley rats. International Journal of Obesity and Related Metabolic Disorders 26 1289-1295.

Flier JS 2004 Obesity wars: molecular progress confronts an expanding epidemic. Cell 116 337-350.

Gasparetti AL, De Souza CT, Pereira-da-Silva M, Oliveira RL, Saad MJ, Carneiro EM \& Velloso LA 2003 Cold exposure induces tissue-specific modulation of the insulin-signalling pathway in Rattus norvegicus. Journal of Physiology 552 149-162.

Ito M, Gomori A, Ishihara A, Oda Z, Mashiko S, Matsushita H, Yumoto M, Sano H, Tokita S, Moriya M, Iwaasa H \& Kanatani A 2003 Characterization of MCH-mediated obesity in mice. American Journal of Physiology - Endocrinology and Metabolism 284 E940-E945.

Kopelman PG 2000 Obesity as a medical problem. Nature 404 635-643.

Ludwig DS, Tritos NA, Mastaitis JW, Kulkarni R, Kokkotou E, Elmquist J, Lowell B, Flier J S \& Maratos-Flier E 2001 Melanin-concentrating hormone overexpression in transgenic mice leads to obesity and insulin resistance. Journal of Clinical Investigation 107 379-386.

Pang DT, Sharma BR \& Shafer JA 1985 Purification of the catalytically active phosphorylated form of insulin receptor kinase by affinity chromatography with O-phosphotyrosyl-binding antibodies. Archives of Biochemistry and Biophysics 242 176-186.

Pereira-da-Silva M, Torsoni MA, Nourani HV, Augusto VD, Souza CT, Gasparetti AL, Carvalheira JB, Ventrucci G, Marcondes MC, Cruz-Neto AP, Saad MJ, Boschero AC, Carneiro EM \& Velloso LA 2003 Hypothalamic melanin-concentrating hormone is induced by cold exposure and participates in the control of energy expenditure in rats. Endocrinology 144 4831-4840.

Qu D, Ludwig DS, Gammeltoft S, Piper M, Pelleymounter MA, Cullen MJ, Mathes WF, Przypek R, Kanarek R \& Maratos-Flier E 1996 A role for melanin-concentrating hormone in the central regulation of feeding behaviour. Nature 380 243-247.

Rojas FA, Hirata AE \& Saad MJ 2003 Regulation of insulin receptor substrate-2 tyrosine phosphorylation in animal models of insulin resistance. Endocrine 21 115-122.

Saad MJ, Araki E, Miralpeix M, Rothenberg PL, White MF \& Kahn CR 1992 Regulation of insulin receptor substrate-1 in liver and muscle of animal models of insulin resistance. Journal of Clinical Investigation 90 1839-1849.

Saltiel AR \& Kahn CR 2001 Insulin signalling and the regulation of glucose and lipid metabolism. Nature 414 799-806.

Schwartz MW, Woods SC, Porte D Jr, Seeley RJ \& Baskin DG 2000 Central nervous system control of food intake. Nature 404 661-671.

Scott AM, Atwater I \& Rojas E 1981 A method for the simultaneous measurement of insulin release and B cell membrane potential in single mouse islets of Langerhans. Diabetologia 21 470-475.

Segal-Lieberman G, Bradley RL, Kokkotou E, Carlson M, Trombly DJ, Wang X, Bates S, Myers MG Jr, Flier JS \& Maratos-Flier E 2003 Melanin-concentrating hormone is a critical mediator of the leptin-deficient phenotype. PNAS 100 10085-10090.

Shimada M, Tritos NA, Lowell BB, Flier JS \& Maratos-Flier E 1998 Mice lacking melanin-concentrating hormone are hypophagic and lean. Nature 396 670-674.

Shulman GI 2000 Cellular mechanisms of insulin resistance. Journal of Clinical Investigation 106 171-176.

Steppel JH \& Horton ES 2004 Beta-cell failure in the pathogenesis of type 2 diabetes mellitus. Current Diabetes Reports 4 169-175.

Torsoni MA, Carvalheira JB, Pereira-Da-Silva M, de Carvalho-Filho MA, Saad MJ \& Velloso LA 2003 Molecular and functional resistance to insulin in hypothalamus of rats exposed to cold. American Journal of Physiology - Endocrinology and Metabolism 285 E216-E223.

Trinder P 1969 Determination of blood glucose using an oxidase-peroxidase system with a non-carcinogenic chromogen. Journal of Clinical Pathology 22 158-161. 
Valladares A, Porras A, Alvarez AM, Roncero C \& Benito M 2000

Noradrenaline induces brown adipocytes cell growth via beta-receptors by a mechanism dependent on ERKs but independent of cAMP and PKA. Journal of Cell Physiology 185 324-330.

Received 7 December 2004

Accepted 13 April 2005 